\title{
Reciclado masivo de la envolvente urbano-edilicia basado en procesamiento digital de imágenes, La Plata, Argentina
}

\author{
Mass retrofitting of \\ building envelope at urban \\ level based on digital \\ image processing, \\ La Plata, Argentina
}

\author{
Graciela Melisa Viegas ${ }^{1}$ \\ ORCID: https://orcid.org/0000-0001-6248-4678 \\ Correo electrónico: gachiviegas@yahoo.com.ar \\ Dante Andrés Barbero ${ }^{1}$ \\ ORCID: https://orcid.org/0000-0002-7820-2388 \\ Pedro Joaquín Chévez ${ }^{1}$ \\ ORCID: https://orcid.org/0000-0001-8437-5026 \\ Irene Martini ${ }^{1}$ \\ ORCID: https://orcid.org/0000-0002-9427-8497 \\ Carlos Alberto Discoli ${ }^{1}$ \\ ORCID: https://orcid.org/0000-0002-6944-5492
}

\begin{abstract}
${ }^{1}$ Instituto de Investigaciones y Políticas del Ambiente Construido - Consejo Nacional de Investigaciones Científicas y Técnicas, Universidad Nacional de La Plata, La Plata, Argentina.
\end{abstract}

Financiamiento: Consejo Nacional de Investigaciones Científicas y Técnicas de Argentina. Comisión Nacional de Actividades Aeroespaciales.

\section{Resumen}

El presente trabajo busca generar soluciones para abordar la problemática del reciclado edilicio masivo del sector residencial a nivel urbano. Para ello, se desarrolla una metodología innovadora orientada a identificar los distintos materiales constructivos de la envolvente urbana-edilicia para realizar estimaciones de ahorro de energía por incorporación de eficiencia energética. Se propone el procesamiento digital de imágenes satelitales SPOT 6 y aéreas a través de clasificaciones. En este caso se clasifican los techos; se determina la calidad de los resultados; y sobre los mejores resultados se aplican estrategias de mejora de la envolvente para su tratamiento masivo a escala urbana. Como caso de aplicación se trabajó con el sector residencial del partido de La Plata, Argentina. Los resultados mostraron que las clasificaciones con imágenes aéreas alcanzan una buena precisión para la complejidad urbana abordada (70 \%). Esto permitió estimar la potencialidad de ahorros de energía anual para calefacción entre 2000 y 3000 $\mathrm{kWh} / \mathrm{año}$ por vivienda, visualizados en forma ágil por medio de cartografía urbana. En efecto, el uso de sensores remotos aplicados al análisis detallado y masivo de áreas urbanas aporta un conocimiento de interés y poco difundido en nuestra región. A su vez, esta metodología puede ser extrapolada a ciudades con características análogas.

\section{Palabras clave}

Eficiencia energética, fotografía aerea, fotografía satelital, Partido de La Plata, reciclaje de la envolvente arquitectónica.

\begin{abstract}
The purpose of this work is to provide solutions for mass retrofitting of building envelope in residential areas at urban level. An innovative methodology is developed that identify the different construction materials of the urban-building envelope in large-scale to estimate energy saving by recycling them with energy efficiency criteria. It is proposed the digital processing of SPOT 6 satellite and aerial images through semi-automatic classifications. In this case, the roofs are classified, the quality of the results is determined, the most appropriate processing is defined, and with these results envelope improvement strategies are applied for mass treatment at urban level. The work was carried out in the residential area of La Plata department, Argentina. The results showed that the classifications with aerial images achieve good precision for the complexity addressed (70\%). This allowed estimating energy savings which can be seen on urban maps easily showing the annual energy saving potentialities for heating between 2000 and $3000 \mathrm{kWh} /$ year per house. In effect, the use of remote sensors applied to the detailed and massive analysis of urban sectors provides a little disseminated knowledge of interest in our region. In turn, this methodology can be applied to cities with similar characteristics.
\end{abstract}

\section{Keywords}

Building envelope recycling, energy efficiency, La Plata department, satellite images.
HISTORIAL DEL ARTÍCULO

Recibido:

05 de junio de 2020.

Aceptado:

01 de diciembre de 2020.
CÓMO CITAR ESTE ARTÍCULO:

Viegas, G.M., Barbero, D.A., Chévez, P.J., Martini, I. y Discoli, C.A. (2020). Reciclado masivo de la envolvente urbano-edilicia basado en procesamiento digital de imágenes, La Plata, Argentina. Revista de Urbanismo, 43, 151-167. https://doi.org/10.5354/07175051.2020 .57522 


\section{Introducción}

A nivel mundial, la demanda de energía destinada a los edificios representa un $23 \%$ de la matriz (International Energy Agency, 2015). Se estima que un 80 \% de la energía total que utiliza un edificio se consume durante su vida útil, mientras que el $20 \%$ restante se consume durante la extracción/fabricación de sus materiales y la ejecución de la obra. El consumo energético en las edificaciones se origina principalmente en los requerimientos de calefacción y refrigeración y depende de la calidad pasiva del edificio y de la eficiencia de los sistemas de acondicionamiento térmico interior. La calidad pasiva se determina por las pérdidas a través de la envolvente edilicia, las pérdidas por ventilación e infiltraciones, las ganancias por radiación solar y producción de calor interno (equipamientos y ocupantes). En este sentido, los países con climas templados y cálidos suelen presentar una mayor demanda de energía que los países con climas fríos, ya que la calidad pasiva es deficiente y la eficiencia energética aún no ha sido integrada al proceso de construcción de edificios, con lo cual tienen un mayor potencial de ahorro. Por tal motivo, resulta de especial interés recuperar los criterios de la arquitectura pasiva en la construcción o la rehabilitación de los edificios, pues representa un gran potencial de ahorro energético (Lloyd Jones, 2002; Wassouf, 2014). La problemática mencionada suele ser abordada desde diferentes escalas de análisis, las cuales van del nivel de componente hasta el urbano.

Desde el nivel urbano, es preciso destacar que las ciudades aglutinan a la mayor parte de las edificaciones, de las actividades industriales y del transporte; todo esto bajo un proceso de urbanización que se desarrolla cada vez con mayor intensidad. En efecto, las ciudades congregan prácticamente la totalidad de la demanda de energía global, la cual es altamente dependiente de la energía fósil. Esta situación, en el marco del contexto energético y climático actual, lleva a la necesidad inmediata de replantear dicha demanda, fundamentalmente en aquellas regiones en donde no se han implementado medidas masivas de eficiencia energética. Por esta razón, las ciudades son, o deberán ser, las principales receptoras de los programas de mejoramiento energético que formulen los diferentes países, provincias o regiones. Estos programas podrán abordar el problema desde los aspectos tecnológicos, pasando por la discusión de la morfología urbana, hasta intervenir en aspectos actitudinales de los y las usuarios/as. Algunos ejemplos son los programas de inserción de energías renovables a escala urbana y eficiencia energética en edificios (nuevos y existentes), programas de estímulos e incentivos para la eficiencia energética, entre otros aspectos (Chévez, Martini, \& Díscoli, 2019).

A modo de contextualización, es preciso señalar que los países del mundo desarrollado comenzaron a replantear sus formas de uso de la energía y estrategias de eficiencia energética en los distintos sectores de la demanda a partir de la crisis petrolera de 1973. En el sector residencial, el proceso se desarrolló primero en la rehabilitación de la edilicia existente con criterios de uso racional, conservación y luego eficiencia energética, para sentar las bases normativas de las construcciones nuevas en base a dicha experiencia. En Europa y Estados Unidos se alcanzaron a comienzos del siglo XXI reducciones del consumo de energía entre el 15 al 45\% en el sector residencial. Como ejemplos relevantes podemos mencionar los casos de España y Francia donde se crearon en 1984 el IDAE (Instituto para la Diversificación y Ahorro de la Energía, 2006) y en 1986 la Agencia de Transición Ecológica (ADEME), respectivamente, como organismos del Estado a través de los cuales se llevaron a cabo acciones de reciclado sistemático de edificaciones para reducir la demanda de energía en el sector residencial. Se realizaron relevamientos, acciones, capacitaciones, guías orientadas a la difusión, alentando al resto de los países a trabajar en consonancia (Rosenfeld, 1993). Con el avance de las medidas y el paso de los años, los países europeos incorporaron el concepto de Passive House Retrofit, que planteó la creación de edificios de muy bajo consumo energético y que permitieron ahorros de energía cercanos al $80 \%$ aplicadas a la rehabilitación edilicia existente (Verbeeck \& Hens, 2005) (Rodríguez González, Díaz, Caamaño, \& Wilby, 2011). Sin embargo, en la actualidad el reciclado o rehabilitación energética de la edificación existente en países del mundo, sigue siendo un tema de interés, tal como se observa en los 
estudios de costo-beneficio de la rehabilitación edilicia en España (Fernández Ans, 2019), en la búsqueda de estrategias de reciclado de viviendas de los años $40 \mathrm{de}$ Roma (de Santoli, Macini, Natasi, \& Ridolfi, 2017), o en la evaluación de medidas de reciclado en viviendas sociales de Argentina (Filippín, Ricard, Flores Larsen, \& Santamouris, 2017). En función de estos ejemplos es posible observar la necesidad de abordar la problemática a escala urbana a partir de la mejora del edificio individual, planteando el desarrollo de investigaciones aplicadas que integren ambas escalas.

Por su parte, desde el diseño de la forma urbana también se aborda el estudio de la problemática. En este sentido, la discusión mundial acerca de la ciudad compacta y la ciudad difusa tiene un largo recorrido. Este debate incluye el análisis respecto al consumo energético, el uso del transporte, la calidad ambiental, el uso del suelo, entre otras variables. Por ejemplo, Rueda-Palenzuela (2019) destaca que la ciudad difusa presenta un mayor consumo energético y de recursos (suelo, materiales, etc.) sin aumentar la complejidad urbana; la cual puede ser entendida como la probabilidad de contactos, intercambios y comunicación. Por su parte, el autor sostiene que la ciudad compacta puede aumentar la complejidad urbana con un menor consumo energético y de espacio. En esta línea de discusión, el trabajo de Li, Song, y Kaza (2018) analiza cómo la densidad edilicia puede influenciar en la reducción del consumo de electricidad en el sector residencial. Similares análisis de densidades edilicias se observan en Poelmans y Rompaey (2009). Por su parte Egusquiza, Prieto, Izkara y Béjar (2018) desarrollan mapas urbanos que co-relacionan el ahorro de energía con los costos de aplicación de estrategias de eficiencia energética. Van Der Hoven \& Wandl (2015) demuestran las relaciones entre la demanda de energía para acondicionamiento de edificios y las condiciones de la edilicia urbana existente, advirtiendo sobre los riesgos de no considerar esta situación en el confort térmico. Finalmente, Rodríguez Álvarez (2016) realiza una síntesis de distintos modelos energéticos urbanos a escala mundial y observa que en general trabajan a partir de clasificaciones tipológicas de edificios, simulaciones térmicas estacionarias o dinámicas de los mismos (en algunos casos recurriendo a programas como el Energy Plus), e integración de la información a través de Sistemas de Información Geográfica, para visualizar los impactos a nivel urbano. Todos estos antecedentes se desarrollan a nivel internacional, pero no se observan a nivel local o latinoamericano.

En el plano local, el sector residencial de Argentina demanda un cuarto del consumo energético nacional, y la mitad de ese consumo corresponde a la climatización de viviendas, lo cual plantea la urgencia de desarrollar acciones para mitigar esta situación mediante un uso más eficiente de los recursos, en una acción conjunta entre el Estado y los individuos de la sociedad. Los elevados consumos se deben principalmente a la baja calidad tecnológico-constructiva de la edilicia, la cual no cumple con los estándares mínimos de habitabilidad establecidos en normativas de aplicación voluntaria y/o eventuales leyes de carácter obligatorio (según la jurisdicción). Al mismo tiempo, la discusión entre los modelos de ciudad más adecuados en términos de consumo energético y aprovechamiento helioenergético aún no ha traspasado la barrera académica, siendo necesaria su implementación en el ambiente construido.

En efecto, se debe mejorar el aprovechamiento de los recursos, y una de las opciones es la conservación y el uso eficiente de la energía lograda a partir del reciclado urbano edilicio. Este es un elemento central y es necesario observarlo en el largo plazo. Por ejemplo, en la ciudad de La Plata, caso de estudio de esta investigación, se incorporan al parque edilicio aproximadamente 5.000 viviendas por año (sobre un total aproximado de 250.000). En efecto, el parque residencial hoy existente, construido sin respetar estándares mínimos de habitabilidad, tendrá un peso del $70 \%$ en 2040 (Chévez, 2018), lo cual sigue representando un valor muy significativo e indica la necesidad ineludible de emprender su mejora. Todo esto, teniendo en cuenta que las nuevas construcciones respeten los mencionados estándares; lo cual, de momento, no sucede. Estos elementos, además permitirían sentar las bases para la futura implementación de fuentes de energías renovables a nivel urbano. En esta línea, a nivel de la región metropolitana de Buenos Aires, a pesar de 
no existir políticas de Estado para dar respuesta a esta situación, se desarrollaron experiencias de investigación y transferencia en el campo del reciclado edilicio con mejora de la eficiencia energética que permitieron establecer antecedentes de relevancia.

Específicamente en el área de estudio de esta investigación, la Región del Gran La Plata, se desarrollaron proyectos sobre la edilicia urbana existente conformando una cartera de pautas y estrategias para el reciclado edilicio residencial mejorando su eficiencia energética. El trabajo propuso posibles medidas de mejora diferenciando los componentes de la envolvente edilicia (muros, pisos, cubiertas, aberturas) y sus variantes constructivas de acuerdo al tipo de vivienda (Díscoli, Martini, Viegas, Barbero, \& Rodríguez, 2016). Asimismo, se han realizado estimaciones de línea de base de consumo energético residencial para el Gran La Plata, y proyecciones a largo plazo de la evolución de este consumo (Chévez, 2018). En síntesis, se ha trabajado tanto con los edificios como unidades constitutivas como con la ciudad en su conjunto.

Los desarrollos mencionados han presentado nuevas necesidades para su continuidad, particularmente en lo relacionado al abordaje del relevamiento masivo de la ciudad y su edilicia. En ese sentido, surgió la necesidad de superar la instancia de relevamiento y desarrollo manual parcela a parcela. En este punto se reconoció la utilidad de los sensores remotos y de las técnicas de procesamiento automático o semi-automático de imágenes urbanas para alcanzar tanto el análisis masivo como el detallado. A partir de esto, es posible plantear nuestra hipótesis de trabajo, la cual indica que: el desarrollo de una metodología basada en el análisis con sensores remotos permitirá estimar y geolocalizar las potenciales mejoras energéticas del conjunto de las envolventes edilicias de toda una ciudad de forma ágil y económica. Esta información de base servirá para que los planificadores urbanos puedan intervenir de manera masiva en la edilicia construida, lo cual en el largo plazo reduciría la demanda energética a escala urbana.

\section{Sensores remotos aplicados al análisis urbano}

Estas herramientas han sido ampliamente utilizadas en distintas áreas del conocimiento, tales como: la ambiental; la agrícola; la climática; el análisis del riesgo; entre otras, pero su difusión en estudios urbanos orientados a la detección de envolventes edilicias es reducida y en algunas regiones inexistentes. Por ejemplo los análisis de imágenes para conocer el estado y ubicación de la vegetación están muy difundidos, como se muestra en de Nova Vázquez, Ibarra y Ramos Ramos (2018). Entre otros antecedentes significativos, podemos mencionar investigaciones que trabajan con imágenes satelitales ópticas multi e hiperespectrales sobre áreas urbanas. Zhang \& Du (2015) utilizan imágenes hiperespectrales realizando zonificaciones funcionales urbanas y suburbanas, analizando la evolución temporal de cambios en las mismas, Voltersen, Berger, Hese y Schmullius (2014), han analizado los tipos de estructuras urbanas obteniendo zonificaciones a nivel de bloques y (Jensen \& Cowen, 1999) han valorado técnicas y materiales disponibles para la realización de análisis urbanos la detección de infraestructura urbana y sub-urbana. El trabajo de Li et al. (2018) se aboca a determinar, a través de técnicas de agrupamiento sobre imágenes satelitales, grupos de edificios representativos de la demanda de energía para acondicionamiento, validado a través de simulaciones detalladas de edificios. Además, varias investigaciones desarrollan el análisis de las firmas espectrales aplicadas a análisis territoriales (Bladridge, Hook, Grove, \& Rivera, 2009; Oliveira, Chaves, Gloaguen y Silva, 2016). Finalmente, se destaca el trabajo de Vázquez Espinoza de los Monteros, Ambrosio Bastián y Sandoval Sánchez (2015) que verifica la calidad obtenida en clasificaciones de cultivos agrícolas utilizando técnicas clásicas de procesamiento de imágenes de baja resolución, definiendo una precisión entre el 70 y el 80 $\%$ en clasificaciones con imágenes multi-espectrales y métodos de clasificación de máxima verosimilitud. Las investigaciones más recientes incorporan el uso de imágenes radar (SAR) para estudios territoriales (Fernández Ordoñez et al., 2020). En síntesis, los sensores remotos se consideran una herramienta esencial para la evaluación, seguimiento y gestión 
Figura 1

Delimitación del Partido de La Plata. Relación con el río de La Plata, las principales vías de acceso y conectividad con el área metropolitana de Buenos Aires

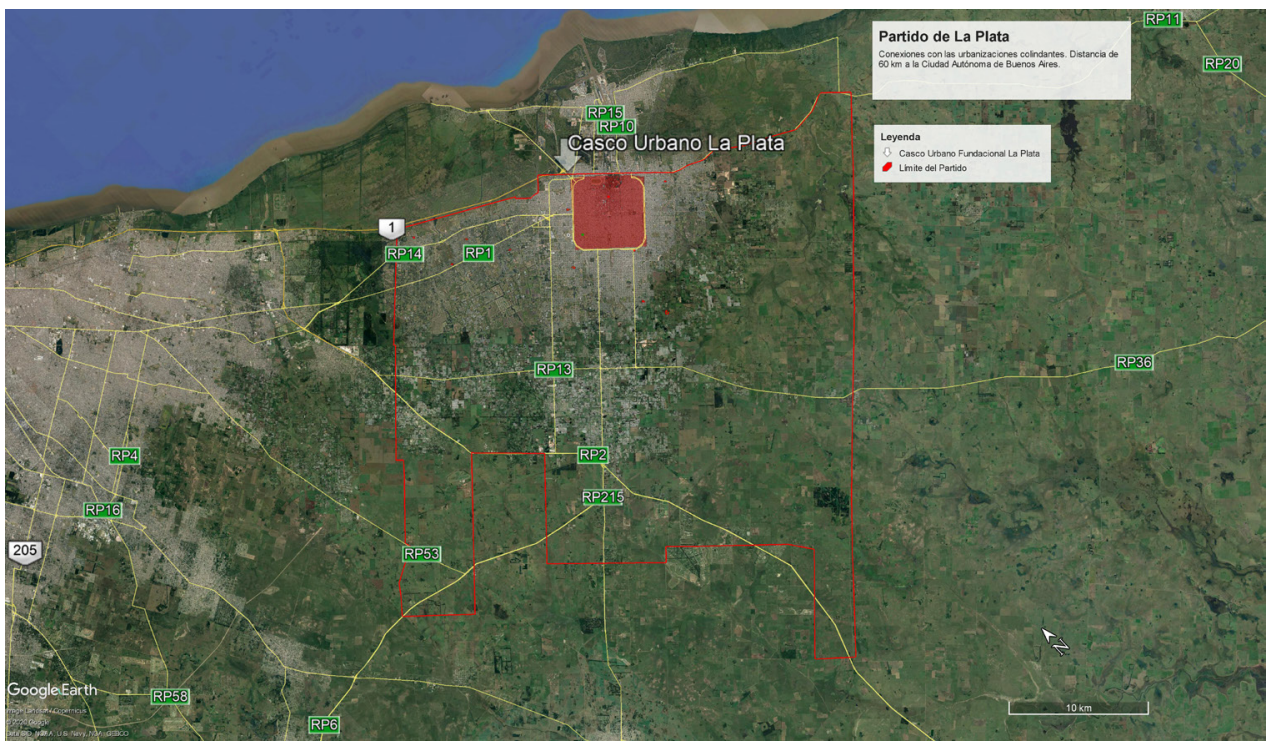

Fuente: Elaboración propia en base a imagen de Google Earth.

del territorio, minimizando las tareas de campo sólo a la verificación y ajustes instrumentales.

A modo de síntesis, estas técnicas permitirían establecer una metodología apropiada para abordar la problemática urbana del reciclado edilicio masivo del sector residencial y automatizar el proceso de relevamiento de la ciudad, reduciendo ampliamente los tiempos de ejecución. En el caso de aplicación, esta es un área de vacancia y se entiende que su aplicación podría realizar un aporte innovador y de gran utilidad para implementar líneas de acción orientadas a mejorar la eficiencia energética en la edilicia existente y reducir la demanda energética a escala urbana.

\section{Objetivos y alcances}

El presente trabajo tiene por objetivo desarrollar una metodología orientada a identificar de manera masiva los distintos materiales constructivos de la envolvente edilicia-urbana dentro de una estructura urbana compleja a partir del procesamiento de imágenes aéreas y/o satelitales ópticas. Dichas imágenes están disponibles en bibliotecas de organismos estatales y se requiere explorar sobre sus potenciales aplicaciones. Se evaluarán distintos procesos de clasificación automáticos y semiautomáticos y se determinará la calidad de los resultados con el objeto de definir los más apropiados.

El trabajo se realizó en el marco de un proyecto1 financiado por el CONICET, cuyo caso de aplicación fue el Partido de La Plata (Figura 1), Buenos Aires, Argentina. Este partido se caracteriza por una geomorfología de llanura (pampeana), se ubica en el Noreste de la provincia de Buenos Aires, a $60 \mathrm{Km}$ de la Ciudad Autónoma de Buenos Aires, a $-34^{\circ} 55^{\prime}$ de latitud (Sur) y a $-57^{\circ} 17^{\prime}$ de longitud (Oeste), con una superficie de $821 \mathrm{Km}^{2}, 15 \mathrm{~m}$ ASNM y un clima templado húmedo.

La ciudad fue fundada en el año 1882 como capital provincial por el Ing. Urbanista Pedro Benoit y es reflejo del urbanismo higienista de finales del siglo XIX (de Paula, 1987). Por su parte, es preciso señalar que su elección como caso de estudio tiene una gran potencialidad de replicabilidad en universos de similares características de Argentina, ya que se define como ciudad intermedia con una importante concentración de población. Desde la fundación a la actualidad se reconocen distintas tipologías edilicias dentro de las cuales, predominan los sistemas tecnológicos constructivos de viviendas de tipo húmedo pesado y semipesado, similar al resto de la provincia y el país, fundamentalmente de ladrillo

1 "Desarrollo de tecnologías y pautas para el reciclado masivo de la envolvente edilicia residencial orientado al uso racional y eficiente de la energía en áreas urbanas" 
cerámico común, la adopción masiva del ladrillo cerámico hueco y las cubiertas inclinadas de chapa galvanizada, de teja cerámica y de pizarra, y las planas de losa de hormigón llena y alivianada o hueca. Por su parte, son muy poco frecuentes los sistemas en seco (Rodríguez, Díscoli y Martini, 2017).

\section{Desarrollo metodológico para la identificación y análisis masivo de los distintos materiales de la envolvente edilicia residencial}

La metodología propone desarrollar estrategias e instrumentaciones complementarias orientadas a identificar y analizar de manera masiva los distintos materiales de los techos de la edilicia residencial, ya que los mismos representarán una determinada calidad térmico-energética y una consecuente demanda de energía. Dichas instrumentaciones se realizan a partir del procesamiento de imágenes satelitales ópticas y aéreas con una buena resolución espectral y espacial. En este sentido, se trabaja a partir de imágenes ópticas del satélite SPOT6, y de imágenes aéreas provistas por el Instituto Geográfico Nacional de Argentina (IGN), obtenidas a través de la Comisión Nacional de Actividades Espaciales (IIPAC-UNLP-CONICET \& CONAE, 2015).

Con respecto a la imagen SPOT 6 (tomada el 12-08-2015), tiene $6 \mathrm{~m}$ de resolución espacial y 4 bandas de resolución espectral (espectro visible e infrarrojo cercano, entre 455 y $890 \mathrm{~nm}$ ), y está provista de una corrección geométrica y se le realiza una corrección radiométrica con el software Envi 5.1, con el objeto de obtener valores de reflectancia de las superficies de los techos en estudio. La detección de la materialidad de los techos se realiza a partir de las firmas espectrales (radiación reflejada en función de la longitud de onda) tomadas de la misma imagen a clasificar. Las firmas espectrales de los materiales son características de cada uno y permiten separar en clases cada tipo de techo.

Por otro lado, se trabajó con imágenes aéreas tomadas entre el 27-03-2013 y el 19-06-2013, con 0,25 m de resolución espacial y 4 bandas de resolución espectral (del visible Azul, verde, rojo, e infrarrojo cercano), la proyección y parámetros utilizados son Gauss-Krügger Faja 6, el marco de referencia (con época) es Posgar 07 - Época 2006.632, la estación de referencia es IGM1 (Ramsac), el sensor de toma de la imagen es Vecxel Ultracam XP. Las mismas fueron procesadas con el programa RStudio, para obtener una clasificación supervisada de los tipos de techos o cubiertas.

Si bien ambas imágenes son de distintas fechas de toma o adquisición, las clasificaciones se realizan indicando qué es cada tipo de superficie y material sobre cada imagen a clasificar. Sin embargo, el sector de la construcción se amplía año tras año, por lo que el trabajo presenta limitaciones en cuanto a la actualización de las superficies construidas.

Para cada clasificación se construyó la correspondiente matriz de confusión a los efectos de determinar los porcentajes de error y aciertos. Con el mejor resultado se trabajó en la aplicación de estrategias de mejoramiento de los techos con criterios de eficiencia energética.

El abordaje metodológico general propuesto se puede sintetizar en las etapas que se desarrollarán a continuación.

Relevamiento manual de los sectores urbanos definidos como casos de estudio.

Conocer el territorio a analizar es clave para las siguientes etapas de validación de la metodología. Este procedimiento apunta a conocer el caso de estudio y justificar la elección de los materiales constructivos que luego serán objeto de análisis a través de las clasificaciones. Para tal fin, se realizó un relevamiento manual por observación visual con imágenes de 0,65 m de resolución espacial, provenientes de Google Earth y Google Street View con el objeto de identificar los materiales constructivos predominantes de la envolvente edilicia residencial en sectores urbanos característicos del área de estudio. De esta manera, una vez identificados, se calculan las superficies de cada tipo de material a través de un Sistema de Información Geográfica (GIS), para luego obtener los valores porcentuales de cada uno en relación con el total. 
Los diez sectores fueron analizados en investigaciones previas desde el comportamiento térmico intraurbano y energético (Viegas, Chévez, San Juan y Díscoli, 2018), y en esta oportunidad se avanza sobre ellos a partir de evaluar sus sistemas constructivos. Los sectores fueron distribuidos en las distintas zonas y conformaciones urbano-edilicias de la ciudad, abarcando tanto el área central denominada Casco Fundacional (CF) como el de su periferia. Se decidió seleccionar 1 área de consolidación 'Alta' (zona del CF), 2 de consolidación 'Media' (periferias cercanas al CF) y 7 de consolidación 'Baja' por ser las mayoritarias en el Partido (áreas periféricas y de borde urbano rural). Las condiciones de FOS, FOT y relación vegetación/construido son variables, abarcando las características del Partido.

\section{Clasificaciones no-supervisada de techos sobre imágenes SPOT6}

Se realiza la clasificación a partir de las firmas espectrales de los materiales constructivos de los techos de edificios tomadas de la misma imagen, a través del algoritmo Spectral Angle Mapper Classification (SAM) del programa Envi 5.1. La firma espectral reúne los valores de radiación reflejada por cada material en cada banda de la imagen (4 valores por material constructivo). El algoritmo determina la similitud entre dos espectros (en este caso la firma espectral del material y el píxel analizado para la clasificación), calculando el ángulo entre ellos, tratándolos como vectores en un espacio con el número de dimensiones igual a la cantidad de bandas espectrales (en este caso 4 bandas). Las clases a detectar son 6, las cuatro primeras las denominamos básicas y las dos restantes complementarias: Techos de Tejas cerámicas rojas; Techos de Chapa galvanizada en buen estado; Techos de Chapa galvanizada oxidada; Techos de Losa de hormigón (blanca o gris); Vegetación; Calle de hormigón.

\section{Clasificación supervisada de techos sobre imágenes aéreas}

Se realiza una clasificación supervisada por el método de Máxima Verosimilitud en el programa RStudio. Para ello se crea un archivo vectorial de polígonos de entrenamiento, el cual contiene 5 muestras por cada clase a detectar. Se utiliza el comando "mlc" - método de Máxima Verosimilitud- al cual se le asigna el archivo de entrenamiento previamente mencionado para que proceda a realizar la clasificación. Se propone clasificar 9 clases observadas previamente en la imagen, ampliando respecto a la anterior debido a la mejora de la resolución espacial de la imagen: Techos de Tejas cerámicas rojas; Techos de Chapa galvanizada en buen estado; Techos de Chapa galvanizada oxidada; Techos de Losa de hormigón

(blanca o gris); Suelo verde; Arbolado; Sombras; Calle de hormigón; Veredas claras.

\section{Verificación de la calidad de las clasificaciones}

Sobre las clasificaciones realizadas (en SPOT6 e imagen aérea) se realiza la verificación de la calidad de estas a través de la construcción de una matriz de confusión que relaciona lo que fue detectado por el clasificador en comparación con lo observado por el operador en el sector de análisis y determina porcentajes de error. La validación se realiza con 500 puntos de verificación distribuidos aleatoriamente en la imagen utilizando el programa QGis, de los cuales la mitad de ellos se reparten equitativamente en las clases y los restantes se reparten en forma proporcional a la frecuencia de aparición de cada clase (se determina la proporción o porcentaje de cada clase respecto al total de las clases de la imagen). Se establecen $9 \mathrm{~m}$ como distancia mínima entre puntos aleatorios debido a la resolución de la imagen de menor resolución espacial (SPOT6: 6 m de resolución espacial). Una vez ubicados en su clase, se verifica si los puntos fueron clasificados correctamente. Cuando alguno de los puntos no corresponde a su clase y tampoco a las restantes (por ejemplo, cuando son otros elementos como personas, vehículos, entre otros), se debe re-muestrear repitiendo el proceso de los puntos aleatorios sólo para estos casos.

Implementación de medidas de ahorro de energía a partir del reciclado de los techos detectados en las imágenes.

Los resultados de la mejor clasificación se exportan a un sistema de información geográfica, excluyendo objetos pequeños por considerarse que no corresponden 
Tabla 1

Condiciones de aislamiento de distintos tipos de techos en la situación base, mejorada y la diferencia entre ambos $(\Delta K)$.

\begin{tabular}{lll}
$\begin{array}{l}\text { Tecnología constructiva con mayor } \\
\text { representatividad en los techos }\end{array}$ & $\begin{array}{l}\text { Aislamiento térmico base } \\
\text { en función del Coeficiente } \\
\text { Volumétrico de Pérdidas K (W/ } / \\
\left.\mathbf{m}^{\mathbf{2}}{ }^{\circ} \mathbf{C}\right)\end{array}$ & $\begin{array}{l}\text { Aislamiento térmico mejorado } \\
\text { en función del Coeficiente } \\
\text { Volumétrico de Pérdidas } \mathbf{K}(\mathbf{W} / \\
\left.\mathbf{m}^{\mathbf{2}}{ }^{\circ} \mathbf{C}\right)\end{array}$ \\
\hline $\begin{array}{l}\text { 1. Techo de teja cerámica roja } \\
\text { 2. Techo de chapa galvanizada (buena y } \\
\text { oxidada) }\end{array}$ & 2,46 & $\begin{array}{l}\text { Diferencia o ahorro potencial } \\
\text { de energía para climatización } \\
\mathbf{\Delta K}\left(\mathbf{W} / \mathbf{m}^{2}{ }^{\circ} \mathbf{C}\right)\end{array}$ \\
\hline 3. Techo de losa de hormigón gris & 2,61 & 0,83 \\
\hline
\end{tabular}

Fuente: Elaboración propia.

a espacios habitables. La capa vectorial de polígonos contiene la siguiente información: a) el tipo de techo (de tejas cerámicas, de chapa galvanizada o de losa de hormigón), b) la superficie y c) la localización geográfica.

A partir de dicha información es posible evaluar el ahorro potencial de energía, identificando las pérdidas térmicas anuales para cada polígono (edificio) que son posibles de evitar por medio del hipotético mejoramiento de la condición de base por una situación mejorada, donde los niveles de aislamiento $\left[\mathrm{K}\left(\mathrm{W} / \mathrm{m}^{2}{ }^{\circ} \mathrm{C}\right)\right]$ de los techos, alcancen los estándares que recomienda la Ley $\mathrm{n}^{\circ} 13.059$ de la Provincia de Buenos Aires sobre Acondicionamiento térmico exigibles en la construcción de edificios (Provincia de Buenos Aires, 2020). Por lo tanto, para cada polígono de la capa vectorial se obtiene la carga térmica anual de calefacción posible de ahorrar por medio del reciclado energético. Para ello se aplica la Ecuación 1 donde el parámetro $\Delta \mathrm{K}$ implica la diferencia entre las condiciones de aislamiento originales del techo y las condiciones mejoradas, para cada una de las tecnologías de techos detectadas, los cuales se expresan en la Tabla 1.

$$
Q(k W h / a \tilde{n} o)=\frac{24 h * G D * \Delta K * \sup }{1000}
$$

- $\quad \mathrm{Q}(\mathrm{kWh} / \mathrm{año})=$ carga térmica anual de calefacción posibles de ahorrar por medio del reciclado edilicio.

- 24 (hs)= horas de climatización diaria

- $\quad \mathrm{GD}\left({ }^{\circ} \mathrm{C}\right)=$ grados día de calefacción $\left(\right.$ Base $\left.18{ }^{\circ} \mathrm{C}\right)$. Partido de La Plata (OBS) $=992$ GD (IRAM, 1996).

- $\Delta \mathrm{K}\left(\mathrm{W} / \mathrm{m}^{2}{ }^{\circ} \mathrm{C}\right)=$ diferencia entre el coeficiente de transmitancia térmica de base y mejorado. Ver Tabla 1.
- $\quad \operatorname{Sup}\left(\mathrm{m}^{2}\right)=$ superficie del techo

- $1 / 1000=$ conversión de $\mathrm{W}$ a kWh

Como resultado, es posible visualizar el ahorro energético en un mapa de gradiente de colores, y también totalizar los valores de kWh/año, posibles de ahorrar por parcela.

\section{Resultados}

A partir de las etapas metodológicas planteadas y sus instrumentaciones se presentan los siguientes resultados obtenidos.

\section{Relevamiento manual de los sectores urbanos definidos como caso de estudio}

La Figura 2 muestra la geolocalización de diez áreas/ tejidos urbanos características del Partido de La Plata y una imagen descriptiva de cada uno, en las cuales se ha relevado la participación porcentual de las distintas envolventes de los techos y coberturas del entorno. Cada tipo de material y cobertura puede presentar variaciones de acuerdo con su estado de envejecimiento ${ }^{2}$ y en cuanto al tipo de terminación. Asimismo, la mayoría de los techos de losa de hormigón, presentan variantes en coloración de sus terminaciones ${ }^{3}$. En forma excepcional, se pueden encontrar techos de tejas de color verde o negras, así como también chapas negras o verdes.

Para esta muestra de conformaciones urbano-edilicias, los techos de chapa de acero galvanizada, teja cerámica roja y losa de hormigón, tienen una representatividad promedio de $68 \%$, $22 \%$ y $10 \%$ respectivamente. A estos materiales se los denomina básicos. Como complemento a estos materiales existen otras coberturas urbanas que se denominan complementarias para las cuales se plantea

2 Por ejemplo, los techos de chapa galvanizada pueden presentar variaciones fundamentalmente si están en buen estado y/o si están envejecidas (oxidadas) con lo cual cambia su coloración y visualización en la imagen.

3 Baldosas rojas, grises, membranas verdes, membranas metalizadas, membranas blancas, etc. 
Figura 2

Sectores urbanos representativos del Partido de La Plata. Mapa de Localización donde se indica la consolidación urbana e imágenes que representan la morfología de cada una. Porcentaje de cada tipo de techo en los diez sectores representativos

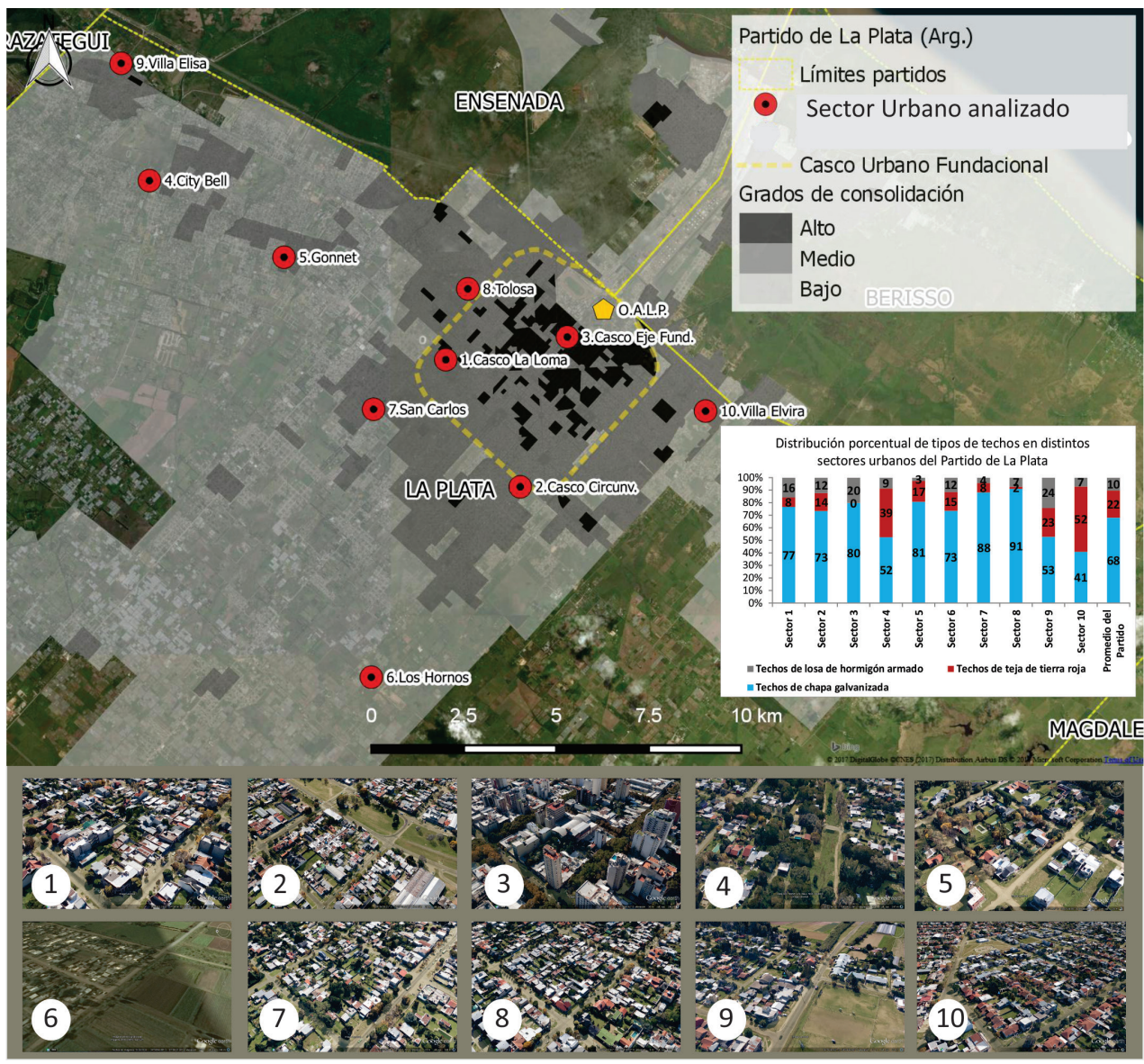

Fuente: Elaboración propia en base a imagen de Google Earth.

su identificación, pero no se las tendrá en cuenta para desarrollar las estrategias de reciclado edilicio porque no corresponden a edificios (vegetación, el asfalto de calles, vereda, sombras, arboledas). Como primera aproximación se puede observar la predominancia de la chapa galvanizada en cuanto a materiales de los techos, siendo sustantivamente mayor y permitiendo delinear las estrategias masivas de mejoramiento de este tipo de tecnologías. Sin embargo, si se realiza un análisis por sector específico observamos que los sectores de la periferia del Partido (Sectores 4, 9 y 10), presentan distribuciones más equilibradas entre los tres tipos de techos y requerirían estrategias particularizadas.

En base a los primeros resultados en forma manual se avanza a partir de la identificación y análisis de las imágenes tipo SPOT en búsqueda de estrategias simplificadas, rápidas y masivas de análisis del sector residencial.

\section{Clasificación no-supervisada de techos sobre imágenes SPOT}

La Figura 3 muestra una clasificación general de las distintas capas obtenidas a partir de los distintos materiales constructivos de los techos y coberturas identificadas en el territorio.

Los resultados permiten observar que es posible identificar en el territorio en forma masiva los distintos materiales constructivos básicos de los techos y coberturas complementarias. La visualización en general es aceptable, y los resultados a nivel particular obtenidos para la clase chapa galvanizada, la chapa galvanizada oxidada y la losa de hormigón se han discriminado razonablemente. Sin embargo, la cobertura de tejas cerámicas rojas ha tomado gran preponderancia en cuanto a su participación respecto del total, en contradicción con el análisis de la 
Figura 3

Clasificación realizada sobre imagen SPOT6 a partir de firmas espectrales de los tipos de techos y coberturas complementarias.

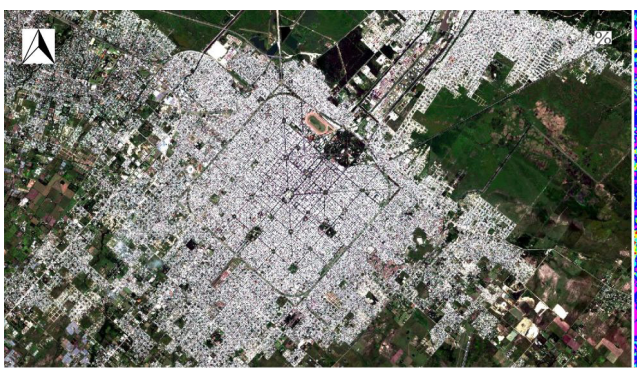

(a)

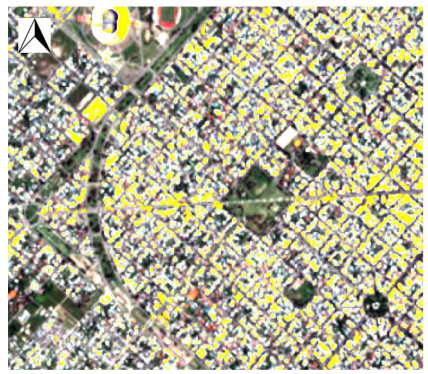

(c)

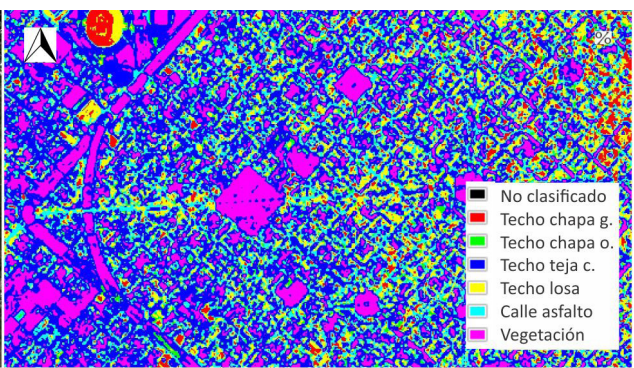

(b)

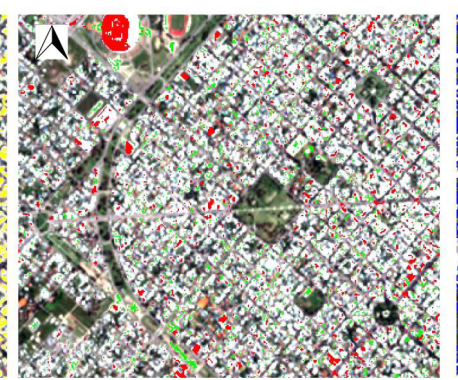

(d)

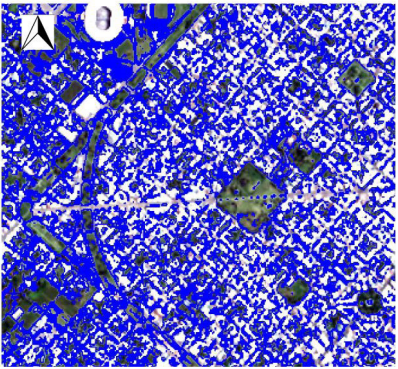

(e)

Nota: (a) Imagen fuente; (b) imagen clasificada y sus clases detallando los resultados sobre el sector 1 de la Figura 2; (c) superficies de losa de hormigón armado; (d) superficies de chapa galvanizada y superficies de chapa galvanizada oxidada (e) superficies de teja cerámica roja.

Fuente: Elaboración propia en base a material provisto por la Comisión Nacional de Actividades Aeroespaciales e Instituto Geográfico Nacional.

Figura 2. Esto se podría atribuir a la relación que existe entre la firma espectral de la teja cerámica roja y su similitud con el asfalto de calles. Se hace necesario entonces identificar otros atributos que permitan diferenciar las tejas del asfalto.

Con estos resultados se avanza en la clasificación de imágenes aéreas con mayor resolución espacial.

\section{Clasificación supervisada de techos con imágenes aéreas}

Al aplicar el método supervisado de máxima verosimilitud sobre una imagen aérea se obtuvo la imagen clasificada como se observa en la Figura 4. Se muestra como resultado un sector de la imagen clasificada correspondiente al sector de conformación urbano-edilicia 1 de la Figura 2.

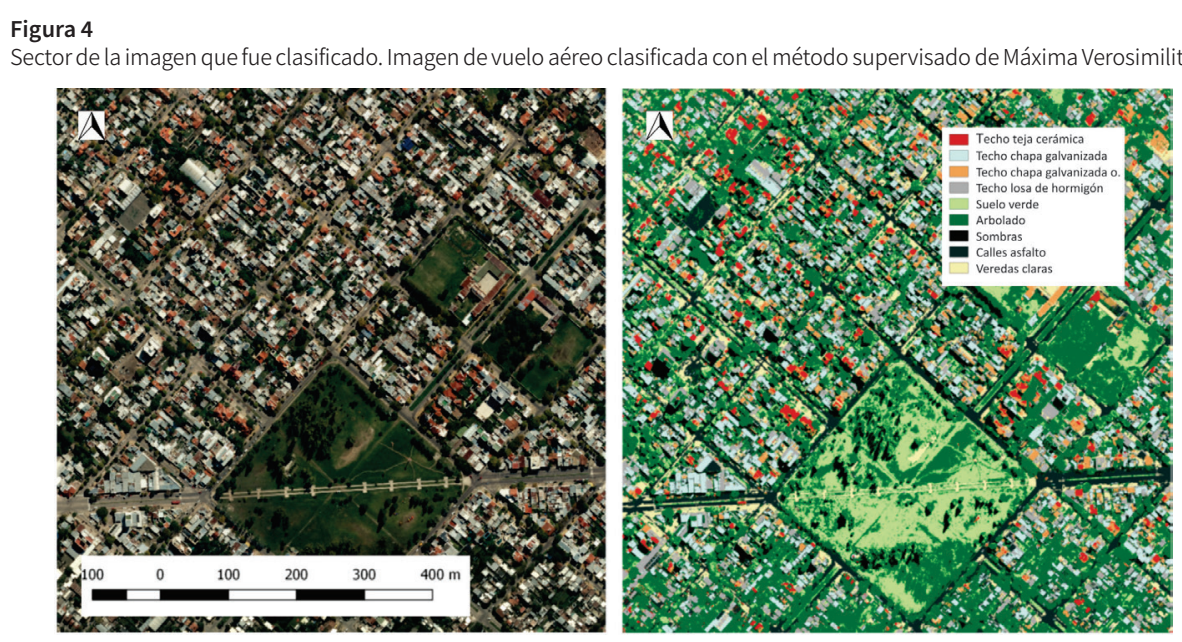

Fuente: Elaboración propia en base a material provisto por la Comisión Nacional de Actividades Aeroespaciales e Instituto Geográfico Nacional. 
Tabla 2

Matriz de confusión de la clasificación de imagen SPOT6 con firmas espectrales. En gris se destacan las clases de interés (techos)

\section{MATRIZ DE CONFUSIÓN} CLASIFICACIÓN IMAGEN SPOT6 OBSERVADO SPOT6 $\left(n^{\circ}\right)$

\begin{tabular}{|c|c|c|c|c|c|c|c|c|c|c|}
\hline & & 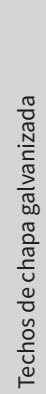 & 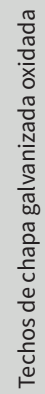 & 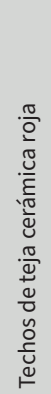 & 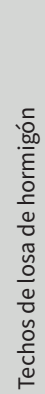 & 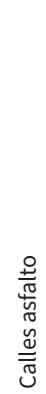 & 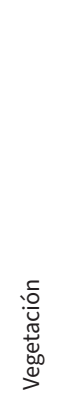 & $\begin{array}{l}\vec{\leftarrow} \\
\stackrel{5}{\circ}\end{array}$ & 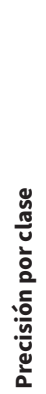 & 흔 \\
\hline \multirow{7}{*}{$\begin{array}{l}\text { DETECTADO } \\
\text { SPOT6 }\left(n^{\circ}\right)\end{array}$} & Techos de chapa galvanizada & 28 & 4 & 0 & 8 & 6 & 0 & 46 & 61 & 39 \\
\hline & Techos de chapa galvanizada oxidada & 5 & 13 & 8 & 17 & 10 & 8 & 61 & 21 & 79 \\
\hline & Techos de teja cerámica roja & 4 & 4 & 4 & 2 & 13 & 33 & 60 & 7 & 93 \\
\hline & Techos de losa de hormigón & 19 & 4 & 0 & 42 & 20 & 2 & 87 & 48 & 52 \\
\hline & Calles asfalto & 37 & 19 & 6 & 44 & 39 & 23 & 168 & 23 & 77 \\
\hline & Vegetación & 0 & 0 & 0 & 1 & 4 & 73 & 78 & 94 & 6 \\
\hline & TOTAL & & & & & & & 199 & 40 & 60 \\
\hline
\end{tabular}

Fuente: Elaboración propia.

Se puede observar que la clasificación mejora sustancialmente respecto a la clasificada sobre imágenes SPOT6. Esto se debe principalmente a que en este caso se combina una resolución espectral similar a la anterior con una resolución espacial significativamente mejor, acorde a la escala detallada que requiere un sector urbano donde las parcelas tienen una medida cuyo lado menor es de aproximadamente $10 \mathrm{~m}$. Como resultado se observan polígonos mucho más definidos que respetan la forma de las edificaciones. La distribución de los distintos tipos de techos se muestra equilibrada, siendo clara la presencia mayoritaria de los techos de chapa galvanizada y la menor presencia de los otros dos tipos de cubiertas, tal como se describe en el gráfico de la Figura 2, sector 1. Sin embargo, es posible percibir algunos errores en la clasificación de las superficies complementarias como las calles de asfalto.

En función de los resultados obtenidos con ambas imágenes, se desarrollan las matrices de confusión para conocer la precisión de estas y conocer el grado de error que se comete al aplicar este tipo de herramientas al caso de estudio considerado en este trabajo.

\section{Estimación de la precisión de las clasificaciones}

En principio se toma la clasificación realizada sobre la imagen SPOT6 del Partido de La Plata y se realiza un recorte más pequeño a través del programa QGis. Sobre el sector se realiza la validación de sus resultados, se construye la matriz de confusión y se calcula la precisión por clase y el error correspondiente, como se observa en la Tabla 2.

Como se puede observar, la precisión total de la clasificación es muy baja (40 \%). En principio podemos atribuirlo a que son pocas las clases elegidas para clasificar, con lo cual hay muchos puntos que deberían, por ejemplo, clasificarse como sombras o como árboles o veredas. Por otro lado, si se consideran las clases de interés, se puede observar que sólo el techo de chapa de acero galvanizado tiene una precisión de $61 \%$, le sigue la losa de hormigón con el 48 \% y la chapa oxidada y la teja (ambas de coloración roja y mayor absortancia térmica) tienen muy baja precisión (21\% y $7 \%$, respectivamente). Este caso es muy particular, ya que se trabajó con una imagen SPOT con tres bandas dentro del espectro visible y una banda infrarroja cercana, con lo cual se esperaba obtener mejores resultados en estas dos clases de materiales que tienen mayor respuesta en el espectro térmico y no en el visible. La clase mejor detectada fue la vegetación, esta situación podemos atribuirla a la presencia de la banda infrarroja de la imagen, ya que a nivel espectral es la que más se diferencia del resto. 
Tabla 3

Matriz de confusión de la clasificación sobre imagen aérea

\section{MATRIZ DE CONFUSIÓN CLASIFICACIÓN IMAGEN AÉREA OBSERVADOS aérea $\left(n^{\circ}\right)$}

\begin{tabular}{|c|c|c|c|c|c|c|c|c|c|c|c|c|c|}
\hline & & 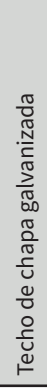 & 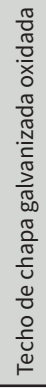 & 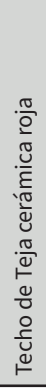 & 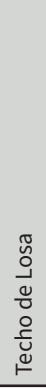 & $\begin{array}{l}\frac{0}{0} \\
\frac{1}{d} \\
\frac{0}{0} \\
\frac{0}{2}\end{array}$ & $\begin{array}{l}\frac{0}{0} \\
\frac{\pi}{0} \\
\frac{0}{2} \\
\end{array}$ & 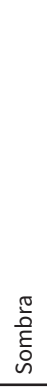 & $\begin{array}{l}0 \\
\frac{ \pm}{\pi} \\
\frac{\pi}{\tilde{N}} \\
\stackrel{0}{0} \\
\stackrel{0}{U}\end{array}$ & $\begin{array}{l}\frac{\pi}{0} \\
\frac{\alpha}{2}\end{array}$ & $\begin{array}{l}\vec{\leftarrow} \\
\stackrel{5}{\circ} \\
\vdash\end{array}$ & 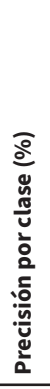 & 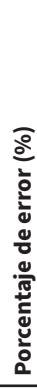 \\
\hline \multirow{10}{*}{$\begin{array}{l}\text { DETECTADO } \\
\text { aéreas }\left(n^{\circ}\right)\end{array}$} & Techo de Chapa galvanizada & 37 & 0 & 0 & 9 & 2 & 0 & 0 & 0 & 0 & 48 & 77 & 23 \\
\hline & Techo de Chapa galvanizada oxidada & 0 & 21 & 16 & 0 & 0 & 0 & 0 & 0 & 0 & 37 & 57 & 43 \\
\hline & Techo de Teja cerámica roja & 1 & 0 & 18 & 6 & 1 & 0 & 2 & 1 & 4 & 33 & 55 & 46 \\
\hline & Techo de Losa & 1 & 3 & 10 & 28 & 0 & 0 & 0 & 0 & 1 & 43 & 65 & 35 \\
\hline & Suelo verde & 0 & 2 & 0 & 0 & 76 & 14 & 0 & 0 & 0 & 92 & 83 & 17 \\
\hline & Arbolado & 1 & 0 & 1 & 2 & 20 & 48 & 34 & 1 & 2 & 109 & 44 & 56 \\
\hline & Sombra & 0 & 0 & 0 & 0 & 0 & 0 & 41 & 0 & 0 & 41 & 100 & 0 \\
\hline & Calle asfalto & 2 & 12 & 0 & 2 & 0 & 0 & 0 & 32 & 5 & 53 & 60 & 40 \\
\hline & Vereda clara & 0 & 0 & 0 & 1 & 0 & 0 & 0 & 1 & 43 & 45 & 96 & 4 \\
\hline & TOTAL & & & & & & & & & & 344 & 69 & 31 \\
\hline
\end{tabular}

Fuente: Elaboración propia.

Con respecto a las particularidades, la clase chapa de acero galvanizada se confundió principalmente con losa de hormigón, siendo esta una respuesta no esperada ya que a nivel espectral son clases opuestas. La chapa de acero galvanizada oxidada se confundió mayoritariamente con la losa de hormigón, mientras que la teja cerámica roja se confundió mayoritariamente con la calle de asfalto y la vegetación, ambas son respuestas esperadas debido a su rango espectral. También la clase losa de hormigón se confundió con la de calle de asfalto (ambos materiales porosos). Como conclusión se puede observar que la utilización de imágenes de 4 bandas, de las cuales 3 pertenecen al espectro visible, no permite discernir correctamente los pares de clases antes mencionados, sobre todo considerando que la resolución espacial no es tan buena. Sin embargo, los resultados verifican que permite aproximarse correctamente a la discriminación de los techos de chapa galvanizada en buen estado, que son los mayoritarios en la región de estudio (ver Figura 2).

A partir de estos resultados se verifica la calidad de la clasificación de la imagen aérea como se puede observar en la Tabla 3.
En la matriz se puede observar que la precisión total es del $69 \%$, lo que se considera aceptable ante la escasa homogeneidad de la superficie que fue clasificada, comparada con la anterior. Hay que considerar que, aun ampliando el número de clases, quedan sectores donde pueden aparecer puntos heterogéneos como vehículos, personas, elementos no reconocibles, equipamiento urbano, otros tipos de cubiertas de techos de menor frecuencia de aparición (otros tipos de losas, tejas, chapas), entre otros, que restringe la posibilidad de mejorar la precisión.

Respecto a las clases específicas y de interés para esta investigación, correspondientes a las cubiertas de los techos (teja, chapa y losa), se observa una precisión de entre $55 \%$ y 77\%, donde la mejor clasificada fue la superficie de chapas de acero galvanizado en buen estado. En esta clase la mayor confusión se da con la clase de losa de hormigón (gris), adjudicándose esta situación a la preponderancia del color frente a otros atributos. La siguiente con mejor clasificación fue la losa de hormigón, con un $65 \%$, la cual se confundió mayormente con teja cerámica (roja), en este caso la confusión puede deberse a la absortancia de las superficies, ambas rugosas y porosas. 
Figura 5

(a) Imagen donde se visualizan sólo las clases de interés para el reciclado edilicio. (b) Ahorro potencial de energía en kWh/año a obtener por la aplicación de estrategias de reciclado edilicio sobre los techos.
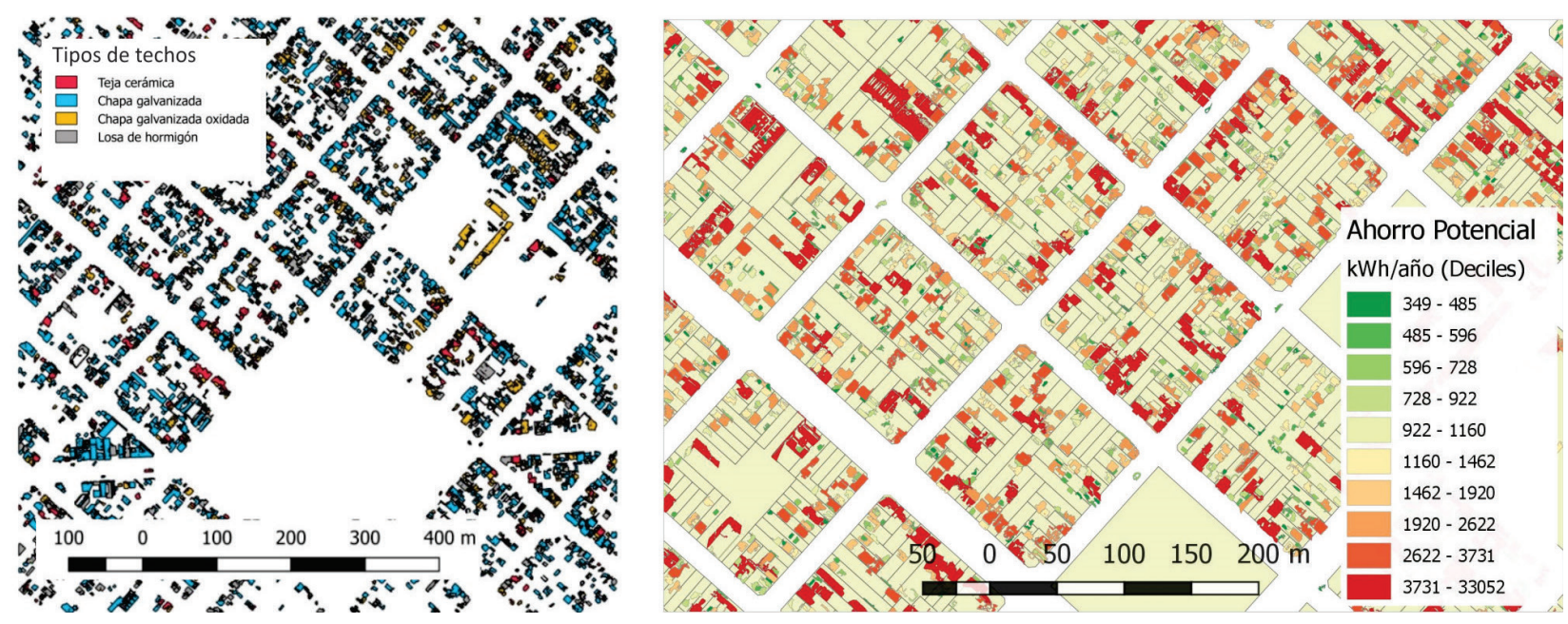

Fuente: Elaboración propia en base a material provisto por la Comisión Nacional de Actividades Aeroespaciales e Instituto Geográfico Nacional.

Las chapas de acero galvanizado oxidadas tuvieron un $57 \%$ de precisión y se confundieron mayormente con la teja cerámica, seguramente debido a su color y emisión térmica. Y finalmente, la de menor precisión fue la clasificación de tejas cerámicas con un $55 \%$, que mayormente se confundió con losa de hormigón y con veredas calcáreas claras, también debido a la absortancia.

A partir de la validación, se han obtenido resultados aceptables en la imagen aérea para realizar estimaciones de reciclado energético sobre las mismas.

\section{Implementación de medidas de ahorro de energía a partir del reciclado de los techos detectados en las imágenes}

En la Figura 5 (a) se observa una imagen resultante de la clasificación sobre imagen aérea donde se han eliminado los sectores pequeños y aislados menores a $9 \mathrm{~m}^{2}$. En la Figura 5 (b) se observa la salida gráfica con los ahorros de energía potenciales de conseguir en cada polígono (techo). Para ello se estima la demanda de energía edilicia a nivel urbano, considerando los sistemas constructivos detectados y se evalúa cuál sería el potencial de ahorro si se aumentaran los niveles de aislamiento térmico integrados a los techos existentes, alcanzando los niveles de aislamiento sugeridos en (Provincia de Buenos Aires, 2020). En la Tabla 4 se observan las superficies de cada tipo de techo obtenidas en un sector urbano.

\begin{tabular}{|c|c|c|c|}
\hline Nombre de la clase & $\begin{array}{l}\text { Superficie } \\
\text { de cada } \\
\text { clase en el } \\
\text { sector }\left(\mathbf{m}^{2}\right)\end{array}$ & $\begin{array}{l}\text { Porcentaje } \\
\text { de cada } \\
\text { clase en el } \\
\text { sector }(\%)\end{array}$ & $\begin{array}{l}\text { Precisión } \\
\text { promedio } \\
\text { obtenida por } \\
\text { clase }(\%)\end{array}$ \\
\hline $\begin{array}{l}\text { Techos de teja } \\
\text { cerámica roja }\end{array}$ & 11.023 & 9 & 55 \\
\hline $\begin{array}{l}\text { Techos de chapas } \\
\text { galvanizadas }\end{array}$ & 74.618 & 62 & 67 \\
\hline $\begin{array}{l}\text { Techos de losa de } \\
\text { hormigón }\end{array}$ & 34.314 & 29 & 65 \\
\hline Total de techos & 124.097 & 100 & 69 \\
\hline
\end{tabular}

Fuente: Elaboración propia.

De acuerdo con la clasificación realizada, se puede observar que la clase mayoritaria es la de chapa galvanizada. Estos techos representan el $62 \%$ del sector; los techos de teja cerámica roja tienen un peso del $9 \%$ y los de losa de hormigón un 29 \%. De acuerdo con la Figura 2, los porcentajes obtenidos por relevamiento manual en la zona de análisis (sector 1) fueron de $77 \%$, 8 \% y $16 \%$ para techos de chapa (en buen estado y añeja), techos de teja cerámica roja y techos de losa de hormigón, respectivamente. Si bien los valores son diferentes, los mismos están en el orden de lo esperado, teniendo en cuenta que se trata de una clasificación semiautomática que no distingue entre los techos y los demás elementos del entorno urbano como vehículos, equipamientos, personas. 
Tal como se puede apreciar, la información espacial puede ser fácilmente asociada a las parcelas individuales o a las manzanas, lo cual permitiría generar un sistema de información muy valioso tanto para los ciudadanos como para el ámbito gubernamental. Por su parte, la graduación de colores permite identificar los puntos más críticos a tratar, siendo los polígonos en rojo intenso aquellos que podrían alcanzar un alto ahorro energético. Se observa la predominancia de potenciales ahorros entre 2000 y $3000 \mathrm{kWh} /$ año en el área urbana estudiada. Si bien en este caso se observa un sector urbano y su detalle, la visualización de la totalidad del medio urbano podría colaborar con la toma de decisiones para la planificación energética urbana.

\section{Discusión}

A partir del desarrollo del presente trabajo es posible afirmar que los procesamientos a través de sensores remotos aplicados al análisis detallado y masivo de los sectores urbanos aportan un conocimiento de interés y poco difundido en la región latinoamericana de acuerdo con lo relevado en la bibliografía. Si bien su utilidad se ha aplicado a distintas áreas del conocimiento, los desarrollos a nivel urbano-edilicio se dan mayoritariamente en países con mayor acceso a la información proveniente de satélites. En este sentido, los avances en la materia aportarán a la mejora de los procesos de análisis y adaptabilidad de estos a la detección y clasificación de materiales y componentes edilicios propios de la región, a la búsqueda de versatilidad en su aplicación, y a la flexibilidad para abordar las complejas problemáticas urbanas de Latinoamérica.

Con respecto a las imágenes disponibles, se pudo observar que las ópticas SPOT6 con 4 bandas espectrales han permitido la identificación y el análisis de los distintos materiales constructivos de techos, para un relevamiento masivo de la envolvente edilicia. Esta metodología de abordaje permitiría reducir los tiempos de procesamiento y realizar estimaciones porcentuales generales del tipo de material para el posterior aumento de la eficiencia energética a partir del mejoramiento de las construcciones existentes y de esta manera aportar a la discusión de la forma urbana y su calidad constructiva como se plantea en Rueda-Palenzuela (2019). Si bien la precisión de la clasificación no es la esperada (40\%), se estima que podría mejorarse incorporando otras coberturas urbanas, eliminando sectores de no interés para el reciclado edilicio, excluyendo las áreas de las coberturas complementarias para luego realizar con mayor precisión la clasificación de los materiales básicos, y/o trabajando a partir de imágenes con mayor resolución espectral, ya que asílos materiales podrían discriminarse con mayor precisión. De igual forma, permiten discriminar los techos de chapa galvanizada con buena precisión (mayor al $60 \%$ ), así como discriminar del suelo urbano las clases de no interés. Asimismo, dichas imágenes tienen beneficios en cuanto a la extensión territorial de las mismas (se puede ver toda la extensión del partido de una ciudad intermedia en una sola toma), a la frecuencia temporal con las que se toman (permite análisis de evolución en distintos años de toma), así como también la facilidad para su procesamiento a gran escala. Por otro lado, es posible obtenerlas de forma gratuita en Argentina, lo cual permite considerarlas como una estrategia viable de utilización de acuerdo con sus limitaciones.

Estas clasificaciones también permiten analizar el crecimiento urbano de forma periódica, precisa, conociendo superficies y materiales existentes. Por todo esto, se considera que aportan al análisis urbano y su rehabilitación energética de forma innovadora en la región latinoamericana, de acuerdo con lo relevado en la bibliografía, ya que podrían acompañar procesos y programas de incentivo a la eficiencia energética e incorporación de energías renovables a nivel urbano.

La mejora en la resolución espacial usando imágenes aéreas $(0,25 \mathrm{~m})$, proporcionó buenos resultados a nivel general (alrededor del $70 \%$ ) considerando la bibliografía relevada, (Vázquez Espinoza de los Monteros, Ambrosio Bastián y Sandoval Sánchez, 2015) donde verificaron calidades de precisión entre el 70 y el 80 \% en cultivos agrícolas (que requieren menor detalle que las edificaciones debido a su extensión) utilizando técnicas clásicas de procesamiento de imágenes de baja resolución. Asimismo, son muy buenos para clasificar las chapas de acero galvanizado (77 $\%)$, que son las mayoritarias en el caso de estudio. Como 
desventaja, las imágenes no se actualizan temporalmente como sucede con las tomadas por satélites. Esta limitación iría en desventaja respecto al planteamiento inicial del problema donde se destacó que las ciudades intermedias y en particular La Plata, tienen un crecimiento estimado de 5000 viviendas al año. Sin embargo, este crecimiento se desarrolla principalmente por extensión de suelo urbano en la periferia, con lo cual las áreas de consolidación media y alta conservan más su morfología y superficies con el paso de los años.

\section{Conclusiones}

El presente trabajo se orientó a generar métodos que permitieran identificar los distintos materiales constructivos de la envolvente para su análisis a nivel urbano. En este caso se analizaron los techos, a partir del procesamiento de imágenes satelitales ópticas y aéreas de la ciudad de La Plata, disponibles en Argentina a través de la Comisión Nacional de Actividades Espaciales (CONAE). Para ello, se evaluaron distintos procesos de clasificación automáticos y semiautomáticos, se seleccionaron y clasificaron las imágenes y se determinó la calidad de cada resultado con el objeto de definir los más apropiados para avanzar en su implementación. A partir de ellos, se pudo evaluar el potencial de superficies edilicias a mejorar energéticamente y posibilitar así el reciclado masivo en el medio urbano. La metodología podría ser desarrollada para otras ciudades de la región latinoamericana con características urbanas similares en cuanto a la consolidación urbano-edilicia.

El desarrollo del relevamiento urbano automático y las estimaciones de ahorro potencial de la demanda de energía permitieron georreferenciar los resultados en la ciudad. En este sentido, se logró graficar a nivel urbano el ahorro energético potencial de las intervenciones de reciclado con un nivel de detalle de parcela, para lo cual se utilizó una escala de colores de lectura ágil e intuitiva. En efecto, es posible afirmar que se verificó la hipótesis de trabajo establecida al inicio de este artículo que indicaba que: el desarrollo de una metodología basada en el análisis con sensores remotos permitirá estimar y geolocalizar las potenciales mejoras energéticas del conjunto de las envolventes edilicias de toda una ciudad de forma ágil y económica

Los resultados mostraron en forma conjunta la escala global y detallada y permitieron cuantificar resultados a partir de operaciones en un SIG. Se observa la predominancia de potenciales ahorros entre 2000 y $3000 \mathrm{kWh} /$ año en el área urbana estudiada. Esta herramienta de visualización dinámica e interactiva señala claramente el potencial del reciclado energético urbano-edilicio lo cual podría ser un servicio para el ciudadano individual que decida efectuar una mejora sobre su propiedad, como así también para acciones colectivas de mejora a nivel urbano. Asimismo, podrían ser una herramienta de gestión gubernamental y para los planificadores de políticas urbano-energéticas, para direccionar un programa de reciclado edilicio en el lugar que genere mayores ahorros energéticos.

Como conclusión respecto de las clasificaciones, el grado de precisión en imágenes satelitales no ha sido tan alto como el de las imágenes aéreas, pero se valora que las mismas trabajan a partir de la clasificación por firmas espectrales, de gran valor y escaso desarrollo en este tipo de análisis urbano, y que tienen disponibilidad temporal de largo plazo. En pos de mejorar esta situación se tienen como líneas de trabajo futuro avanzar en la obtención de imágenes multiespectrales como medio para mejorar la discriminación de las distintas materialidades de las cubiertas, incorporando mayor espectro. Como ejemplo, las imágenes Sentinel (12 bandas de resolución espectral, $443 \mathrm{~nm}$ a $2190 \mathrm{~nm}$, resolución espacial de 6, 20 y 60 m) y especialmente las imágenes World View II (8 bandas de resolución espectral, $400 \mathrm{~nm}$ a $1040 \mathrm{~nm}$, resolución espacial de 1,9 m). Con respecto a las imágenes aéreas, los resultados se consideraron satisfactorios y se espera avanzar en un protocolo de acción que pueda ser transferido a distintos organismos del Estado que lo requieran.

\section{Referencias bibliográficas}

Bladridge, A. M., Hook, S. J., Grove, C. I., \& Rivera. (2009). The ASTER spectral library version 2.0. Remote Sensing of Environment, 113(4), 711-715. https://doi.org/10.1016/j.rse.2008.11.007 
Chévez, P. (2018). Construcción de escenarios urbanoenergéticos a partir de la implementación de estrategias de eficiencia energética y energías renovables en el sector residencial (Tesis doctoral). Universidad Nacional de Salta. Salta, Argentina.

Chévez, P., Martini, I., \& Díscoli, C. (2019). Methodology developed for the construction of an urban-energy diagnosis aimed to assess alternative scenarios: An intra-urban approach to foster cities' sustainability. Applied Energy, 237, 751-778. https://doi.org/10.1016/j. apenergy.2019.01.037

Díscoli, C. A., Martini, I., Viegas, G. M., Barbero, D., \& Rodríguez, L. (2016). Pautas para el reciclado masivo de la envolvente edilicia residencial. Urbano (33), 54-65.

Egusquiza, A., Prieto, I., Izkara, J. L., \& Béjar, R. (2018). Multiscale urban data models for early-stage suitability assessment of energy conservation measures in historic urban areas. Energy \& Buildings, 164, 87-98. https://doi. org/10.1016/j.enbuild.2017.12.061

Fernández Ans, P. (2019). Coste óptimo y viabilidad económica de la rehabilitación energética de viviendas en España. Hábitat Sustentable, 9(2), 64 -77. https://doi.org/10.223 20/07190700.2019.09.02.06

Fernández Ordoñez, Y., Soria Ruiz, J., Leblon, B., Macedo Cruz, A., Ramírez Guzmán, M., \& Escalona Maurice, M. (2020). Imágenes de radar para estudios territoriales, caso: inundaciones en Tabasco con el uso de imágenes SAR Sentinel-1A y Radarsat-2. Realidad, datos y espacio revista internacional de estadística y geografía, 11(1), 4-21.

Filippín, C., Ricard, F., Flores Larsen, S., \& Santamouris, M. (2017). Retrospective analysis of the energy consumption of single-family dwellings in central Argentina. Retrofitting and adaptation to the climate change. Renewable Energy, 101, 1226-1241. https://doi.org/10.1016/j. renene.2016.09.064
Instituto para la Diversificación y Ahorro de la Energía. (2006). Memoria Anual. Madrid: Autor. https://www.idae. es/uploads/documentos/documentos_10586_Memoria_ anual_2006_A2007_49d1aecb.pdf

International Energy Agency. (2015). Indicadores de Eficiencia Energética:Bases Esenciales para el establecimiento de políticas. Paris: Autor. http://biblioteca.olade.org/opactmpl/Documentos/cg00333.pdf

IIPAC-UNLP-CONICET y CONAE. (2015). Convenio Específico Desarrollo de tecnologías de detección, identificación y clasificación de características urbano-edilicias sobre imágenes satelitales aéreas y SAR. La Plata.

Jensen, J. R., \& Cowen, D. C. (1999). Remote Sensing of Urban/ Suburban Infrastructure and Socio-Economic Attributes. In Martin Dodge, Rob Kitchin, and Chris Perkins (Eds.), The Map Reader (pp. 153-163). Wiley Online Books. https://doi.org/10.1002/9780470979587.ch22

Li, C., Song, Y., \& Kaza, N. (2018). Urban form and household electricity consumption: A multilevel study. Energy \& Buildings, 158, 181-193. https://doi.org/10.1016/j. enbuild.2017.10.007

Li, X., Yao, R., Liu, M., Costanzo, V., Yu, W., \& Wang, W. (2018). Developing urban residential reference buildings using clustering analysis of satellite images. Energy \& Buildings, 169, 417-429. https://doi.org/10.1016/j. enbuild.2018.03.064

Lloyd Jones, D. (2002). Arquitectura y entorno: el diseño de la construcción bioclimática. Blume.

de Nova Vázquez, E., Ibarra, G. C., \& Ramos Ramos, H. (2018). Identificación de la vegetación urbana de la Ciudad de México; evaluación de cuatro métodos para la determinación de umbrales en el índice normalizado de diferencias de vegetación y de la clasificación supervisada. Realidad, datos y espacio. Realidad, datos yespacio revista internacional de estadística y geografía, 9(3), 65-83. 
Oliveira, T. M., Chaves, J. M., Gloaguen, T. V. y Silva, T. B. (2016). Geotecnologías, herramientas para la construcción de una nueva visión del cambio global y su transformación para un futuro sostenible. Biblioteca espectral de solos e rochas do greenstonebelt rio itapicuru. Actas del XVII Simposio Internacional SELPER (pp. 1989-1997). Foz Do Iguazú: SELPER.

de Paula, A. (1987). La Ciudad de La Plata, sus tierras y su arquitectura. La Plata: Ediciones del Banco de la Provincia de Buenos Aires, Argentina.

Poelmans, L., \& Rompaey, A. (2009). Detecting and modelling spatial patterns of urban sprawl in highly fragmented areas: A case study in the Flanders-Brussels region. Landscape and Urban Planning, 93, 10-19. https://doi. org/10.1016/j.landurbplan.2009.05.018

Provincia de Buenos Aires. (4 de julio de 2003). Ley Provincial $N^{\circ} 13.059$ de la PBA. Boletín Oficial. https://normas.gba. gob.ar/ar-b/ley/2003/13059/3792

Rodríguez Álvarez, J. (2016). Urban Energy Index for Buildings (UEIB): A new method to evaluate the effect of urban form on buildings energy demand. Landscape and Urban Planning, 148, 170-187. https://doi.org/10.1016/j. landurbplan.2016.01.001

Rodríguez González, A., Díaz, V., Caamaño, J., \& Wilby, M. (2011). Towards a universal energy efficiency index for buildings. Energy and Buildings, 43(4), 980-987. https:// doi.org/10.1016/j.enbuild.2010.12.023

Rodríguez, L. G., Díscoli, C. A. y Martini, I. (2017). Criterios y métodos para el reciclado edilicio con eficiencia energética. La Plata: Arte editorial servicop.Rosenfeld, E. (1993). Mejoramiento de las Condiciones Energéticas y de Habitabilidad del Hábitat Bonaerense. La Plata: CONICET.

Rueda-Palenzuela, S. (2019). El urbanismo ecosistémico. Ciudad y territorio. Estudios Territoriales, LI(202), 723-752. https://recyt.fecyt.es/index.php/CyTET/article/view/77733 de Santoli, L., Macini, F., Natasi, B., \& Ridolfi, S. (2017). Energy retrofitting of dwellings from the 40's in Borgata Trullo - Rome. Energy Procedia, 133, 281-289. https:// doi.org/10.1016/j.egypro.2017.09.389

Van Der Hoven, F., \& Wandl, A. (2015). Amsterwarm: Mapping the landuse, health and energy-efficiency implications of the Amsterdam urban heat island. Building Service Engineering Research Technology, 36 (1), 67-88. https:// doi.org/10.1177/0143624414541451

Vázquez Espinoza de los Monteros, R. A., Ambrosio Bastián, J. y Sandoval Sánchez, G. A. (2015). Clasificación de cultivos agrícolas utilizando técnicas clásicas de procesamiento de imágenes y redes neuronales artificiales. Realidad, datos y espacio revista internacional de estadística y geografía, 6(3), 62-77.

Verbeeck, G., \& Hens, H. (2005). Energy savings in retrofitted dwellings: economically viable? Energy and Buildings, 37(7), 747-754. https://doi.org/10.1016/j.enbuild.2004.10.003

Viegas, G. M., Chévez, P. J., San Juan, G. A., \& Díscoli, C. A. (2018). Comportamiento energético de mosaicos urbanos representativos (La Plata-Buenos Aires-Argentina): influencia de las variaciones térmicas intraurbanas. Ambiente Construido, 18(3), 175-194. http://dx.doi. org/10.1590/s1678-86212018000300275

Voltersen, M., Berger, C., Hese, S., \& Schmullius, C. (2014). Object-based land cover mapping and comprehensive feature calculation for an automated derivation of urban structure types at block level. Remote Sensing of Environment, 154, 192-201. https://doi.org/10.1016/j. rse.2014.08.024

Wassouf, M. (2014). De la casa pasiva al estándar Passivhaus. Barcelona: Gustavo Gili.

Zhang, X., \& Du, S. (2015). A Linear Dirichlet Mixture Model for decomposing scenes: Application to analyzing urban functional zonings. Remote Sensing of Environment, 169, 37-49. https://doi.org/10.1016/j.rse.2015.07.017 